\title{
Hormonal changes during parturition in heifers and goats are related to the phases and severity of labour
}

\author{
E Hydbring, A Madej, E MacDonald ${ }^{1}$, G Drugge-Boholm, \\ B Berglund ${ }^{2}$ and $\mathrm{K}$ Olsson
}

Department of Animal Physiology, Swedish University of Agricultural Sciences, Uppsala, Sweden

${ }^{1}$ Department of Pharmacology and Toxicology, University of Kuopio, Finland

${ }^{2}$ Department of Animal Breeding and Genetics, Swedish University of Agricultural Sciences, Uppsala, Sweden

(Requests for offprints should be addressed to E Hydbring, Department of Animal Physiology, Swedish University of Agricultural Sciences, Box 7045, S-750 07 Uppsala, Sweden)

\begin{abstract}
Parturition is a natural event that involves stress and pain for the mother. We thus hypothesized that levels of stress hormones measured during parturition could reflect levels reached in response to severe discomfort and pain of other kinds as well. The aim of this study was therefore to determine whether plasma concentrations of cortisol, adrenaline, noradrenaline, $\beta$-endorphin, met-enkephalin, vasopressin and oxytocin vary depending on the phase and severity of labour in dairy heifers (ten) and dairy goats (six), and how these hormones interact with each other. Blood samples were taken once a day for 3 days before labour and for 3 days afterwards and at predetermined phases during labour. All heifers delivered one calf and five of them needed obstetrical assistance. Two of the goats delivered one kid, and four had twins; all kidded without help. The cortisol concentration peaked when the calf and the first kid were born. In the heifers, plasma adrenaline increased after delivery, while the noradrenaline concentration did not change significantly in heifers that needed assistance, but increased during expulsion in heifers calving without help. In the goats, adrenaline and noradrenaline concentrations increased in association with expulsion of the first kid. The
\end{abstract}

$\beta$-endorphin concentration increased during labour in goats. In heifers that needed assistance, $\beta$-endorphin concentration increased $1 \mathrm{~h}$ after labour but there was no change in heifers that did not need assistance. The met-enkephalin concentration was elevated during expulsion in heifers and fluctuated in the goats. Both oxytocin and vasopressin increased during expulsion in both groups of heifers, but vasopressin increased four times more in heifers needing assistance. In the goats, oxytocin reached its highest levels just as the feet of the first kid became visible, and vasopressin peaked as the head emerged. Parturition took longer in heifers that needed assistance than in those that did not. It is concluded that, even though the pattern of change differed between hormones during labour, the changes were related to the phases of labour. A longer labour therefore meant that the hormone concentrations stayed elevated for longer. Vasopressin reached high levels in goats and was the only hormone for which plasma concentrations were higher in heifers that needed assistance than in those that did not, indicating that this hormone is released in order to deal with the painrelated stress associated with labour.

Journal of Endocrinology (1999) 160, 75-85

\section{Introduction}

A number of physiological variables, including levels of various hormones, have been analysed in order to objectively evaluate the effects of a stressful situation. This study is part of an ongoing investigation aimed at finding better ways to evaluate well-being in animals. Parturition is a natural event that involves stress and pain for the mother. We thus hypothesized that levels of stress hormones measured during parturition could reflect levels reached in response to severe discomfort and pain of other kinds as well. Although parturition-induced changes in plasma concentrations of stress hormones, e.g. cortisol, opioids and catecholamines, have aroused considerable interest, the interrelations among plasma concentrations of these hormones in relation to the severity of labour are still not clear. It is often the case that blood sampling techniques, sampling time, etc. vary from study to study, which makes comparisons difficult. Therefore we decided to withdraw blood at the same predetermined phases of labour in heifers and goats in order to characterize changes in plasma concentrations of cortisol, adrenaline, noradrenaline, $\beta$-endorphin, met-enkephalin, vasopressin and oxytocin, and to relate these changes to the severity and time of labour. To the best of our knowledge, these hormones have never previously been measured in the same samples during each phase of parturition in heifers and goats. 
It is generally accepted that the perception of pain is similar in human beings and other mammals; therefore it can be assumed that what is painful in humans is also painful in animals (Soma 1985, Kitchell 1987). In women, a direct correlation between plasma cortisol levels and the duration of labour has been observed (Burns 1970). Bacigalupo et al. (1990) reported that pain intensity, scored by women during spontaneous labour, correlated positively with the concentration of plasma $\beta$-endorphin and cortisol. Plasma levels of cortisol and $\beta$-endorphin are elevated during labour in cattle (Hudson et al. 1975, Aurich et al. 1993) and goats (Hydbring \& Olsson 1995), but there are no reports of any correlations between these hormones and the severity of labour in ruminants.

Oxytocin is released simultaneously with vasopressin in many situations, but the hormones are also released independently (Chard 1971, Fuchs \& Saito 1971, Kasting 1988). Although the importance of oxytocin in labour has been documented, less is known about the role of vasopressin. High levels of vasopressin are found in foetal blood during birth, but reports on changes in the mother are conflicting (Forsling et al. 1979, Leake \& Weitzman 1979). Vasopressin can be regarded as a stress hormone since it is released in connection with various types of stress, e.g. restraint and use of a nasogastric tube (Nyman et al. 1996), dehydration and haemorrhage (Carter \& Altemus 1997), heavy exercise (Wade 1984) and parturition (Kendrick et al. 1991).

In a previous investigation involving three of the goats in this study, we found that blood pressure and heart rate during parturition rose in parallel with increases in plasma adrenaline and noradrenaline concentrations (Hydbring et al. 1997). Changes in these parameters correlated with the phases of labour, with peak values registered during expulsion of the first kid. In the present study, we wanted to determine how plasma adrenaline and noradrenaline concentrations correlated with plasma cortisol, $\beta$-endorphin, met-enkephalin, vasopressin and oxytocin concentrations during each phase of labour in heifers and goats.

\section{Materials and Methods}

\section{Animals and experimental procedure}

Both the heifers and goats were well adapted to being handled. The care of the animals and the experimental design of the study were approved by the local animal ethics committee in Uppsala.

\section{The heifers}

Ten dairy heifers (26-35 months old), six of the Swedish Red and White (SRB) and four of the Swedish Friesian (SLB) cattle breed, were studied. Close to calving, the animals were fed $5 \mathrm{~kg}$ silage, $2.5 \mathrm{~kg}$ hay and $5 \mathrm{~kg}$ concentrates each day. Calving was estimated to occur 280 days after insemination. Blood samples were removed by venipuncture, once a day at $0900 \mathrm{~h}$, beginning 10-15 days before the estimated calving time, and 3 days after calving. When calving was imminent (i.e. $1-5$ days before the first labour pains were observed), the heifers were moved to a calving box in accordance with normal routines. The box was located in the same barn, and the animals remained there until 1 day after calving. At least $1 \mathrm{~h}$ before the first blood sample was withdrawn, a permanent catheter (SweVet; Piab, Sjöbo, Sweden) was inserted under local anaesthesia (Xylocaine; Astra, Södertälje, Sweden), provided with an extension tube that was fixed to the neck with adhesive tape. It was therefore possible to withdraw blood without having to restrain the animal. Because of the large variations in the length of parturition and its occurrence at any time of day or night (Berglund et al. 1987), we decided to take the blood samples during predetermined phases of labour, the beginning of each of which was defined as follows: (1) first labour pains observed (i.e. the heifer started to show signs of restlessness, such as stumbling, turning her head towards her abdomen, an increased frequency of postural changes and a stiff tail with tail flick); (2) synchronized abdominal contractions begin; (3) first amniotic membrane observed; (4) feet of the calf emerge; (5) head emerges; (6) calf born; (9) 5 min after birth; (10) $1 \mathrm{~h}$ after birth. (N.B. phases 7 and 8 refer to the birth of the second animal, which only occurred with the goats; see below.) To simulate as normal conditions as possible, we decided beforehand that the experienced stable foremen should determine whether and when the animals needed assistance, according to the normal routines.

\section{The goats}

Six dairy goats of the Swedish domestic breed (Capra hircus), 2-4 years old, were studied. They were kept individually in pens with straw as bedding material and were given $600 \mathrm{~g}$ hay and $200 \mathrm{~g}$ of a concentrate mixture at 0700 and $1500 \mathrm{~h}$. Water was available at all times. Two of the goats were primiparous and four were multiparous. Blood samples were taken by venipuncture, once daily at $1030 \mathrm{~h}$ from day 144 until kidding and for 3 days thereafter. When we suspected that parturition was close, the neck of the goat was shaved and cleaned, and a permanent catheter (Secalon; Viggo Products, Helsingborg, Sweden) was inserted, as described above. Blood was sampled during each of the labour phases defined for heifers, as well as phases associated with expulsion of the second kid, i.e. starting when the second amniotic membrane was expelled (7). The phases when the feet of the second kid and head emerged and the second kid was born occurred so rapidly that these phases were represented by a single sample (8). 
Table 1 Data on RIAs used

\begin{tabular}{|c|c|c|c|}
\hline & $\begin{array}{l}\text { Lower } \\
\text { detection } \\
\text { limit }\end{array}$ & $\begin{array}{l}\text { Intra-assay } \\
\text { coefficient } \\
\text { of variance }(\%)\end{array}$ & $\begin{array}{l}\text { Interassay } \\
\text { coefficient of } \\
\text { variance }(\%)\end{array}$ \\
\hline \multicolumn{4}{|l|}{ RIA (unit) } \\
\hline Cortisol (nmol/l) & $6 \cdot 5$ & $<12 \cdot 5$ & $\begin{array}{l}\text { Low } 14.5 \\
\text { Medium } 1.5 \\
\text { High } 3\end{array}$ \\
\hline$\beta$-Endorphin $(\mathrm{pmol} / \mathrm{l})$ & 3 & $<11$ & $\begin{array}{l}\text { Low } 8 \cdot 5 \\
\text { Medium } 9 \cdot 5\end{array}$ \\
\hline Met-enkephalin $(\mathrm{pmol} / \mathrm{l})$ & 29 & $<15$ & $\begin{array}{l}\text { Low } 13 \cdot 5 \\
\text { Medium } 15 \cdot 5\end{array}$ \\
\hline Vasopressin $(\mathrm{pmol} / \mathrm{l})$ & 1 & $<15$ & $\begin{array}{l}\text { Low } 27 \\
\text { Medium } 25 \cdot 5 \\
\text { High } 6 \cdot 5\end{array}$ \\
\hline Oxytocin (pmol/l) & $2 \cdot 5$ & $<12 \cdot 5$ & $\begin{array}{l}\text { Low } 25 \\
\text { Medium } 8.5 \\
\text { High } 21\end{array}$ \\
\hline
\end{tabular}

\section{Analyses}

Blood was withdrawn into ice-chilled tubes containing EDTA (tripotassium salt) and aprotinin (Trasylol; Bayer, Leverkusen, Germany; 5000 Kallikrein-Inhibitor-Units/ $10 \mathrm{ml}$ tube), centrifuged at $1500 \mathrm{~g}$ for $20 \mathrm{~min}$ at $4{ }^{\circ} \mathrm{C}$, and stored at $-20{ }^{\circ} \mathrm{C}$ for $24 \mathrm{~h}$ and thereafter at $-80{ }^{\circ} \mathrm{C}$ until assayed. Dilutions of bovine and caprine plasma were parallel to the standard curve in all RIAs described below. Plasma cortisol was measured using the Coat-A-Count RIA (Diagnostics Product Corporation, Los Angeles, CA, USA), and plasma $\beta$-endorphin was extracted and analysed according to the plasma $\beta$-endorphin ${ }^{125}$ I RIA kit (Incstar, Stillwater, MN, USA). Plasma met-enkephalin was extracted and analysed according to instructions in the methionine enkephalin ${ }^{125}$ I RIA kit (Incstar) with one exception; $1 \mathrm{ml}$ decanting suspension (sheep anti-rabbit, no 3; Pharmacia \& Upjohn Diagnostics, Uppsala, Sweden) was used instead of ammonium sulphate. Before arginine vasopressin and oxytocin were analysed, the plasma was extracted with acetone (Guarantee Reagent (GR); Merck, Darmstadt, Germany) and petroleum benzene (GR; boiling point range $40-60{ }^{\circ} \mathrm{C}$; Merck) with a recovery of $92 \%$. Vasopressin was then analysed using the vasopressin RIA (Bühlmann Lab AG, Allschwil 1, Switzerland). Oxytocin was determined in principal as described by Stock \& Uvnäs-Moberg (1988), but modified and validated for caprine and bovine plasma. Thus rabbit antiserum XS 3014 (Euro-Diagnostica AB, Malmö, Sweden) was diluted 1:28000 in the incubation phosphate buffer (pH 7.6) with 0.005\% Tween 80. Bound and free ligands were separated by adding $1 \mathrm{ml}$ decanting suspension (sheep anti-rabbit no. 3). See Table 1 for further data on the RIAs used. Plasma catecholamine concentrations were determined by HPLC coupled to coulometric detection, as previously described (Hydbring et al. 1997).
Statistical analysis

Values are presented as means \pm s.E.M. All hormonal data were statistically analysed using the General Linear Model procedure from the Statistical Analysis System program package (SAS Institute Inc. 1996). For both heifers and goats, the test for differences in least squares means was used to identify the sampling occasions on which level of a given hormone differed from that on day 3 before labour. The model for analysing the heifer data included the effects of treatment (assistance versus no assistance), within-treatment variation, sampling time and the interaction between treatment and sampling time. Withintreatment variation between heifers was used as an error term when testing for differences between the assistance and no-assistance group. Time differences between the two heifer groups were analysed by Kruskal-Wallis oneway ANOVA. The Pearson correlation coefficient was applied to investigate correlations between the hormones within each labour phase and group of animals. $P \leq 0 \cdot 05$ was considered significant in all analyses. An inspection of the data from individual heifers did not reveal any difference between breeds.

\section{Results}

\section{Time and severity of parturition}

The actual duration of pregnancy in the heifers ranged from 270 to 289 days, and all heifers delivered one calf. Five of the heifers needed assistance (four SRB and one SLB). Light pulling by one person was used for four calves and moderate pulling by two persons was needed for the fifth calf. All calves were in the normal position. Intervention was used only in cases where there was no visible progress once the amniotic membrane (one heifer) or the 
Table 2 Duration of labour $(\mathrm{min})$ in heifers receiving obstetrical assistance $(n=5)$ and those not requiring such assistance $(n=4$; times for one heifer were missing). Values are means \pm S.E.M.

\begin{tabular}{|c|c|c|}
\hline & Assistance & No assistance \\
\hline Time elapsed between first labour pains and birth of the calf & $416 \pm 100^{*}$ & $181 \pm 41$ \\
\hline Time elapsed between first labour pains and synchronized abdominal contractions & $268 \pm 101$ & $95 \pm 34$ \\
\hline Time elapsed between appearance of amniotic membrane and feet of the calf & $37 \pm 9 \cdot 9^{*}$ & $9 \pm 2 \cdot 3$ \\
\hline Time elapsed between emergence of feet of the calf and head & $75 \pm 29$ & $20 \pm 4 \cdot 2$ \\
\hline Time elapsed between head emerging and the birth & $12 \pm 2 \cdot 8$ & $7 \cdot 5 \pm 1 \cdot 2$ \\
\hline
\end{tabular}

${ }^{*} P \leq 0 \cdot 05$ vs no assistance group. Differences in duration of labour between the two animal groups were analysed by Kruskal-Wallis one-way ANOVA.

feet of the calf were visible (four heifers). Four of the heifers had weak abdominal contractions. The fifth heifer had a narrow birth canal. Parturition took significantly longer in heifers needing assistance. The phase lasting from the point at which the amniotic membrane became visible until the feet of the calf appeared was significantly longer in heifers that needed assistance than in those that did not $(P<0 \cdot 05$, Table 2$)$.

The duration of pregnancy in the goats ranged from 146 to 151 days. Two of the goats delivered a single kid, and four had twins. All goats kidded without assistance. The time from first labour pains until the last kid was born was $225 \pm 63 \mathrm{~min}$.

For both heifers and goats, labour took place at all times of the day and night.

\section{Plasma hormone concentrations}

In both heifers and goats, cortisol concentration increased in association with labour pains, continued to rise during expulsion and peaked when the calf or first kid was born. One day after parturition, the concentration had returned to preparturition values (Fig. 1a and b). There were no significant differences in cortisol concentration between heifers needing assistance and those that did not.

In the heifers, adrenaline concentration increased after calving in both groups (Fig. 2a). The concentration of noradrenaline varied greatly between heifers needing assistance, and the change was not significant, whereas the noradrenaline concentration increased significantly during expulsion in the group that did not receive help (Fig. 3a). Mean plasma adrenaline and noradrenaline concentrations were consistently higher in heifers needing assistance than in those that did not, but there was a large amount of individual variation in the former group, which could be one reason why no significant differences were found between groups. In the goats, concentrations of both adrenaline and noradrenaline increased during expulsion (Figs $2 \mathrm{~b}$ and $3 \mathrm{~b}$ ).

In heifers needing assistance, $\beta$-endorphin concentration increased $1 \mathrm{~h}$ after labour. There were no signifi- cant changes in heifers that did not receive help, but the concentration tended to increase in association with the first labour pains (Fig. 4a). There were no significant differences in $\beta$-endorphin concentrations between heifers needing assistance and those that did not, although the concentration tended to be higher in heifers needing assistance as early as 3 days before labour. In the goats, the concentration of plasma $\beta$-endorphin increased during the synchronized labour pains and remained high throughout parturition (Fig. 4b)

In the heifers, met-enkephalin concentrations increased during expulsion of the calf in both groups (Fig. 5a). There was no significant difference in met-enkephalin concentrations between the groups. In the goats, the concentration of met-enkephalin fluctuated and was significantly elevated 2 days before kidding, during the expulsion of the first kid and after kidding (Fig. 5b).

In the heifers the concentration of vasopressin increased during expulsion in both groups, but became four times higher in heifers needing assistance (Fig. 6a). In the goats, the vasopressin concentration increased during the expulsion of the first kid and then decreased slightly, but was still elevated when the second kid was born and at the time of sampling $5 \mathrm{~min}$ afterwards (Fig. 6b).

In both groups of heifers, plasma oxytocin concentration increased during expulsion of the calf. After the calf was born, the values rapidly decreased (Fig. 7a). There was no significant difference in oxytocin values between groups. In the goats, plasma oxytocin concentration was significantly increased in connection with the appearance of the first amniotic membrane, peaked when the feet of the first kid emerged and thereafter started to decrease (Fig. $7 b$ ).

\section{Correlation between plasma hormone levels}

Although plasma concentrations of all investigated hormones increased during parturition, their patterns of change appeared to differ. Therefore we were interested to determine if, and when, positive correlations existed between concentrations of any of the seven hormones during labour (i.e. in blood samples from phases 1-8). 

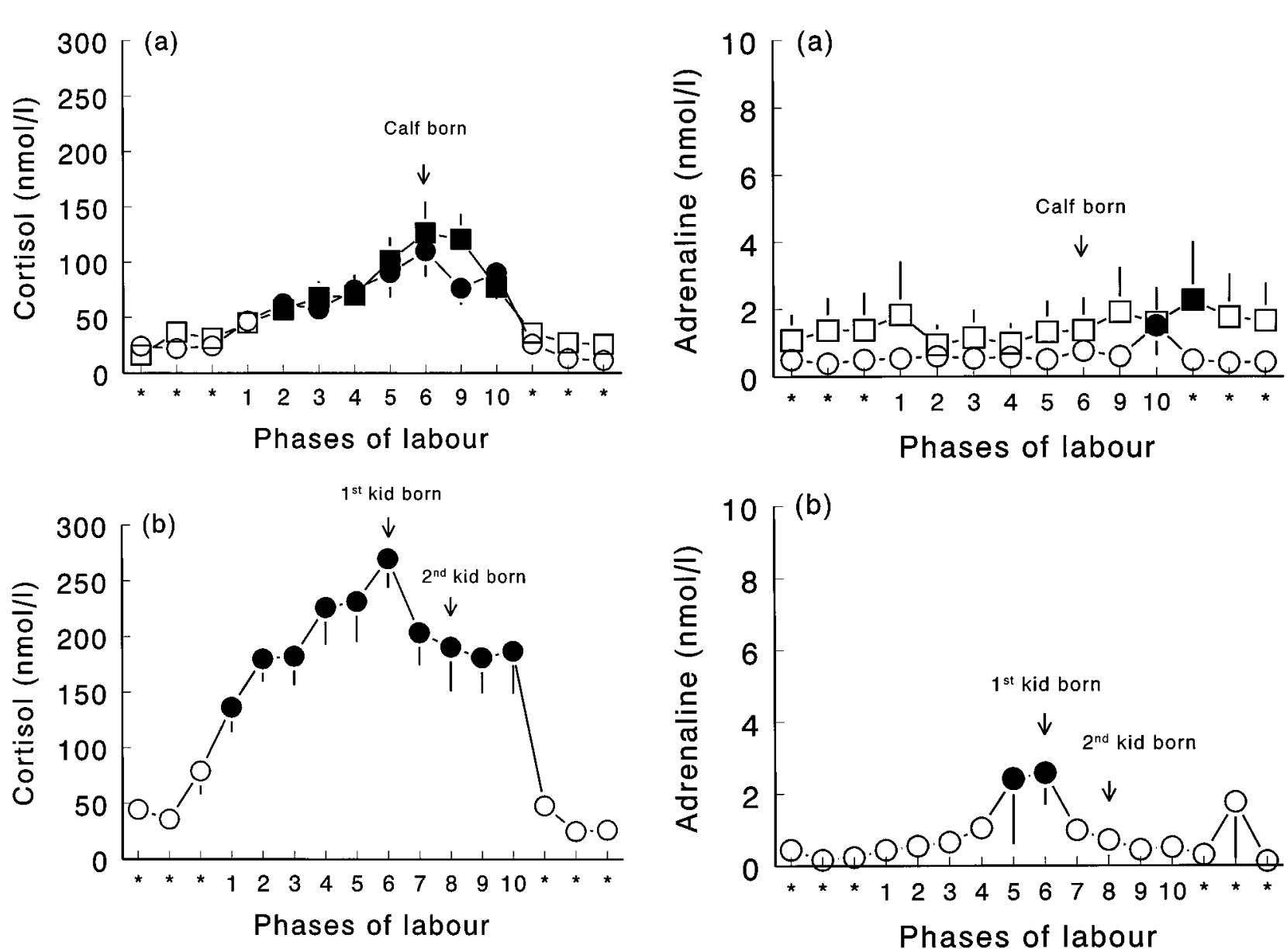

Figure 1 Plasma cortisol concentration during parturition in five heifers that calved without help $(\bigcirc)$, five heifers that needed obstetrical assistance ( $\square$ ) (a) and six goats that kidded without help (b). Each number on the $x$-axis represents the different phases of labour at which blood samples were taken. The beginning of each phase was defined as follows: (1) first labour pains observed; (2) synchronized abdominal contractions begin; (3) first amniotic membrane observed; (4) feet of first kid (calf) emerge; (5) head emerges; (6) first kid (calf) born; (7) second amniotic membrane observed; (8) feet of second kid and head emerge and second kid born; (9) 5 min after birth; (10) $1 \mathrm{~h}$ after birth. *3, 2, 1 days before and 1, 2, 3 days after birth. All heifers had one calf. Two goats delivered one kid and four delivered twins. Values are means \pm S.E.M. Filled symbols indicate that values are significantly different from those on day 3 before parturition $(P \leq 0.05)$. There were no significant differences between the two heifer groups. The S.E.M. values varied between 1.9 and 23.8 in heifers that calved without help, between 2.6 and 28.4 in heifers that needed obstetrical assistance, and between 3.6 and 39.9 in the goats.

In heifers that needed assistance, adrenaline and noradrenaline showed significant positive correlations during every phase of labour $(r=+0 \cdot 95$ to $0 \cdot 99)$. Adrenaline also correlated with met-enkephalin $(r=+0 \cdot 96)$, vasopressin $(r=+0.96)$ and oxytocin $(r=+0.95)$ when the feet of the calf emerged. Noradrenaline correlated with $\beta$-endorphin

Figure 2 Plasma adrenaline concentration during parturition in five heifers that calved without help $(\bigcirc)$, five heifers that needed obstetrical assistance $(\square)$ (a), and six goats that kidded without help (b). Values are means \pm S.E.M. There were no significant differences between the two heifer groups. The S.E.M. values varied between 0.04 and 0.9 in heifers that calved without help, between 0.6 and 1.7 in heifers that needed obstetrical assistance, and between 0.04 and 1.8 in the goats. See Fig. 1 for further details.

when the head emerged $(r=+0 \cdot 88)$ and with metenkephalin $(r=+0.99)$, vasopressin $(r=+0.99)$ and oxytocin $(r=+0 \cdot 99)$ when the feet of the calf appeared. In this phase met-enkephalin also correlated with vasopressin $(r=+0.99)$ and oxytocin $(r=+0.99)$, and so did vasopressin and oxytocin $(r=+0 \cdot 99)$.

In heifers that did not need assistance, the correlation between hormones was much less consistent. There were no correlations between adrenaline and noradrenaline. Positive correlations were found between plasma cortisol and oxytocin during the abdominal contractions $(r=$ +0.99 ), between noradrenaline and vasopressin when the head emerged $(r=+0 \cdot 99)$, and between noradrenaline and oxytocin when the first amniotic membrane was observed 

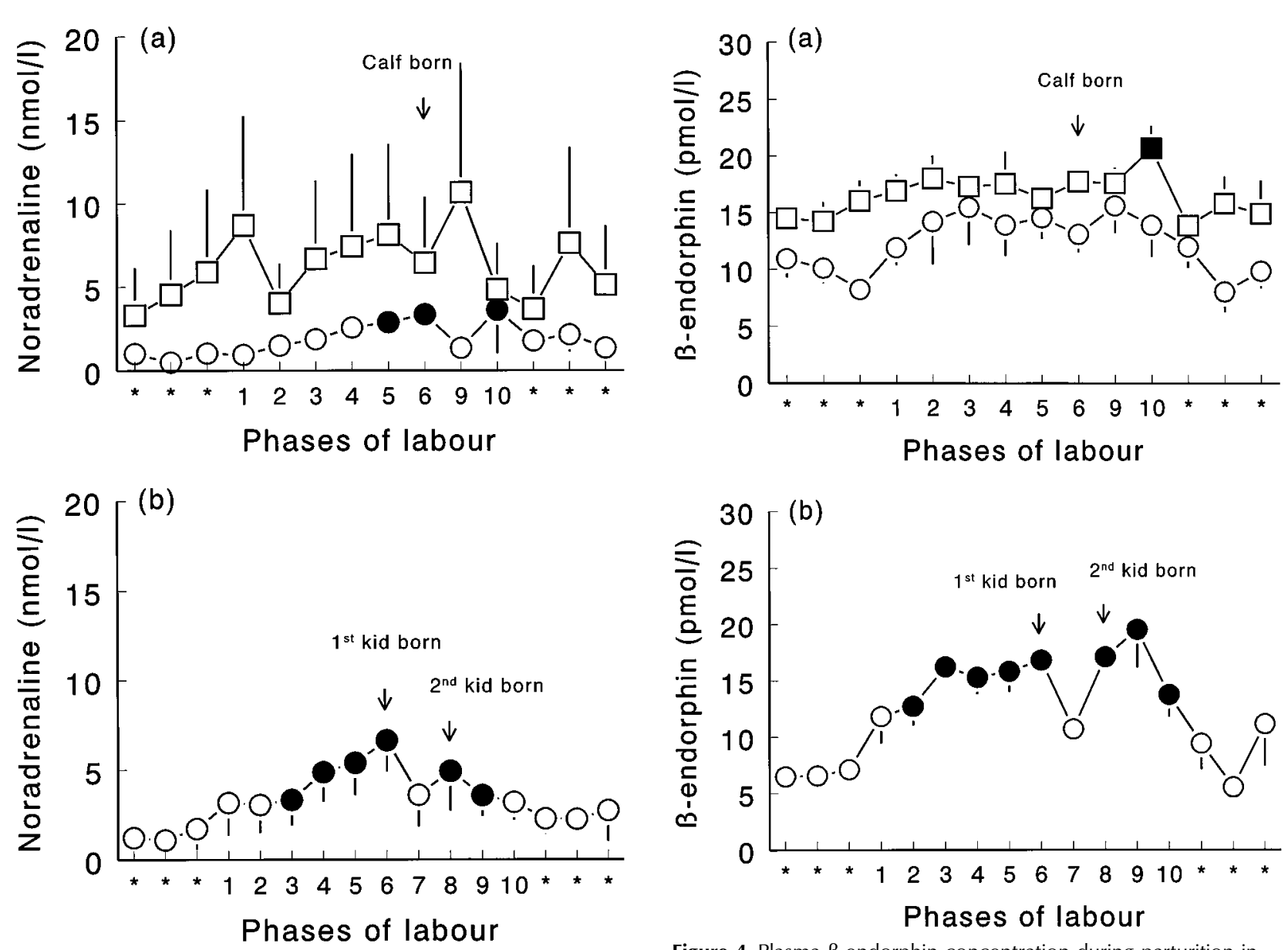

Figure 3 Plasma noradrenaline concentration during parturition in five heifers that calved without help $(\bigcirc)$, five heifers that needed obstetrical assistance $(\square)$ (a), and six goats that kidded without help (b). Values are means \pm S.E.M. There were no significant differences between the two heifer groups. The S.E.M. values varied between $0 \cdot 1$ and $2 \cdot 6$ in heifers that calved without help, between $2 \cdot 4$ and $7 \cdot 7$ in heifers that needed obstetrical assistance, and between 0.6 and $2 \cdot 2$ in the goats. See Fig. 1 for further details.

$(r=+0 \cdot 98) . \beta$-Endorphin correlated with met-enkephalin when the first amniotic membrane was observed $(r=$ $+0 \cdot 90)$.

In the goats, adrenaline and noradrenaline levels correlated when the first amniotic membrane was observed and when the first kid was born $(r=+0 \cdot 88$ to $0 \cdot 94)$. Adrenaline correlated with met-enkephalin when the first amniotic membrane was observed $(r=+0 \cdot 90)$, and noradrenaline correlated with met-enkephalin during most of the expulsion phases of both kids $(r=+0.90$ to $0 \cdot 99)$. $\beta$-Endorphin correlated with oxytocin during the first labour pains $(r=+0 \cdot 83)$, and vasopressin and oxytocin concentrations correlated during the abdominal contractions and when the first amniotic membrane was observed $(r=+0.90$ to 0.99).

Figure 4 Plasma $\beta$-endorphin concentration during parturition in five heifers that calved without help $(\bigcirc)$, five heifers that needed obstetrical assistance $(\square)$ (a), and six goats that kidded without help (b). Values are means \pm S.E.M. There were no significant differences between the two heifer groups. The S.E.M. values varied between 1.1 and 3.8 in heifers that calved without help, between 0.8 and 2.9 in heifers that needed obstetrical assistance, and between $0 \cdot 8$ and $3 \cdot 7$ in the goats. See Fig. 1 for further details.

\section{Discussion}

Recently, we reported that arterial blood pressure, heart rate, plasma adrenaline and noradrenaline concentrations reached peak levels during expulsion of the kids in goats and that the changes were not related to the duration or severity of labour (Hydbring et al. 1997). In the present study we have demonstrated, in addition, that all measured hormones in both heifers and goats change with the phase of labour regardless of its duration. Furthermore, heifers that needed assistance had longer labours and higher concentrations of vasopressin than those not needing assistance. Interestingly, in the assisted heifers, almost all hormone concentrations mutually correlated during the actual expulsion (i.e. in blood samples from phase 4), in contrast with the other heifer group. 

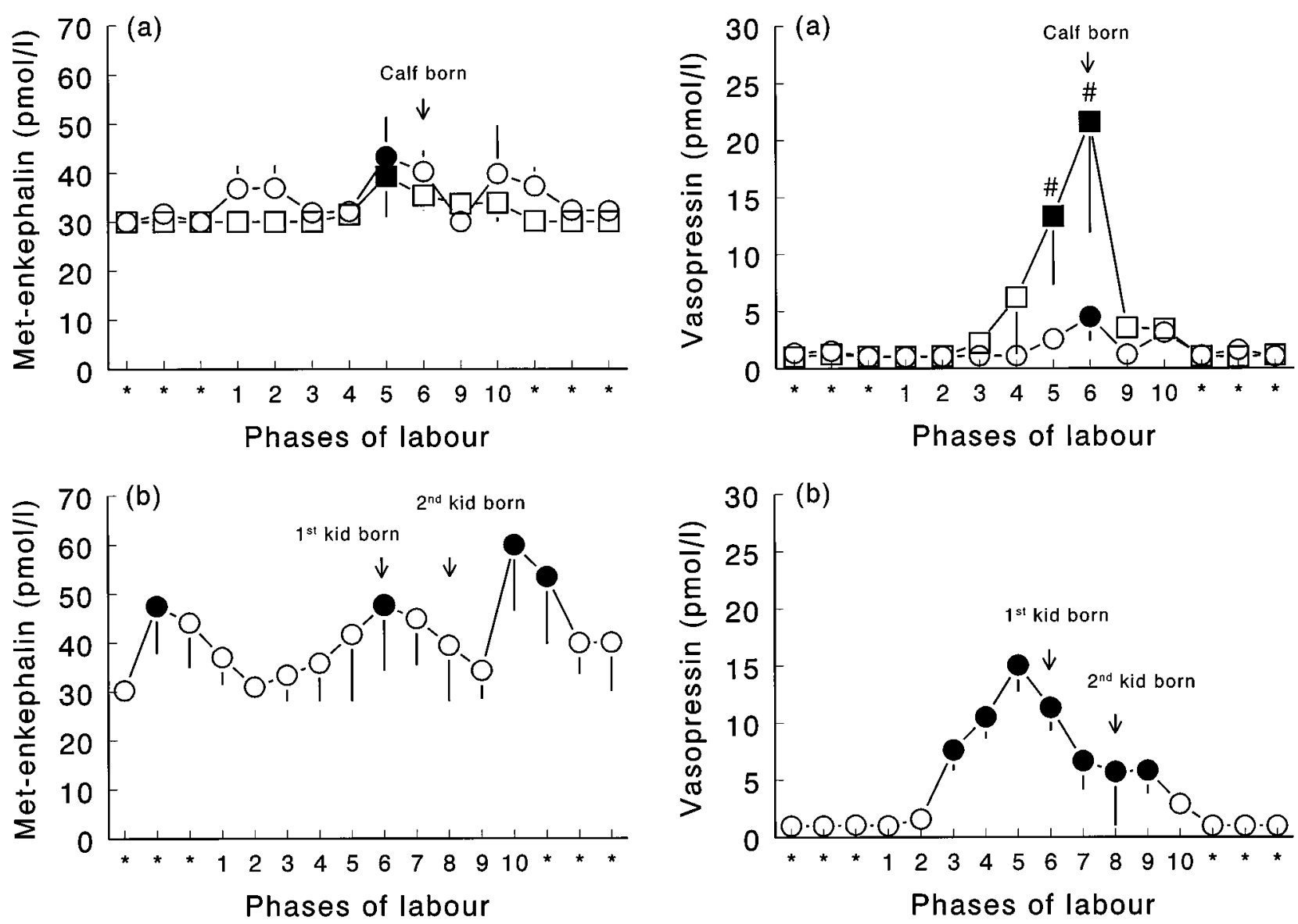

Figure 5 Plasma met-enkephalin concentration during parturition in five heifers that calved without help $(\bigcirc)$, five heifers that needed obstetrical assistance $(\square)$ (a), and six goats that kidded without help (b). Values are means \pm S.E.M. There were no significant differences between the two heifer groups. The S.E.M. values varied between 0.0 and $9 \cdot 8$ in heifers that calved without help, between 0.0 and 8.3 in heifers that needed obstetrical assistance, and between 1.4 and 13.8 in the goats. See Fig. 1 for further details.

Elevated plasma cortisol concentrations, measured at different times around parturition, have previously been reported in cattle (Hudson et al. 1975, Seren et al. 1977, Heuwieser et al. 1987, Taverne et al. 1988, Rausch et al. 1989), goats (Hydbring \& Olsson 1995) and sheep (Strott et al. 1974). Now, through frequent blood sampling, we have also demonstrated that the cortisol increases during parturition in heifers and goats correlate strongly with the phases of parturition. The elevation of cortisol levels around parturition may be due to the increased need for glucocorticoids, to accelerate mammary growth and initiate lactation, and the fact that oestrogens reduce the metabolic clearance rate of cortisol (Kitts 1985). However, the short-lasting peak values around expulsion cannot be explained in this way. Maternal and foetal endocrine changes that lead to the onset of labour are well known

Figure 6 Plasma arginine vasopressin concentration during parturition in five heifers that calved without help $(O)$, five heifers that needed obstetrical assistance $(\square)$ (a), and six goats that kidded without help (b). Values are means \pm S.E.M. ${ }^{\#}$ Significant difference between groups. The S.E.M. values varied between $0 \cdot 02$ and $2 \cdot 1$ in heifers that calved without help, between 0.02 and $9 \cdot 7$ in heifers that needed obstetrical assistance, and between 0.0 and 4.7 in the goats. See Fig. 1 for further details.

and have been detailed in many papers (Barragry 1975, Cox 1975, McFeely \& Ganjam 1976, Challis et al. 1977, Flint et al. 1978, Challis \& Mitchell 1981, Brooks \& Challis 1988, Thorburn et al. 1991, Wood \& Keller-Wood 1991, McMillen et al. 1995). In sheep, an increase in the activity of the foetal hypothalamo-pituitary-adrenal axis initiates parturition (Liggins et al. 1977). However, Apostolakis et al. (1991) found no relation between foetal and maternal cortisol concentrations. In another study on sheep it was found that only small amounts of cortisol escaped from the foetal circulation to the mother (Comline et al. 1970). Therefore it is unlikely that the increased cortisol levels found in the goats and heifers were due to the high cortisol concentrations probably present in their foetuses.

Even though there were no differences in cortisol concentrations between heifers that needed assistance and 

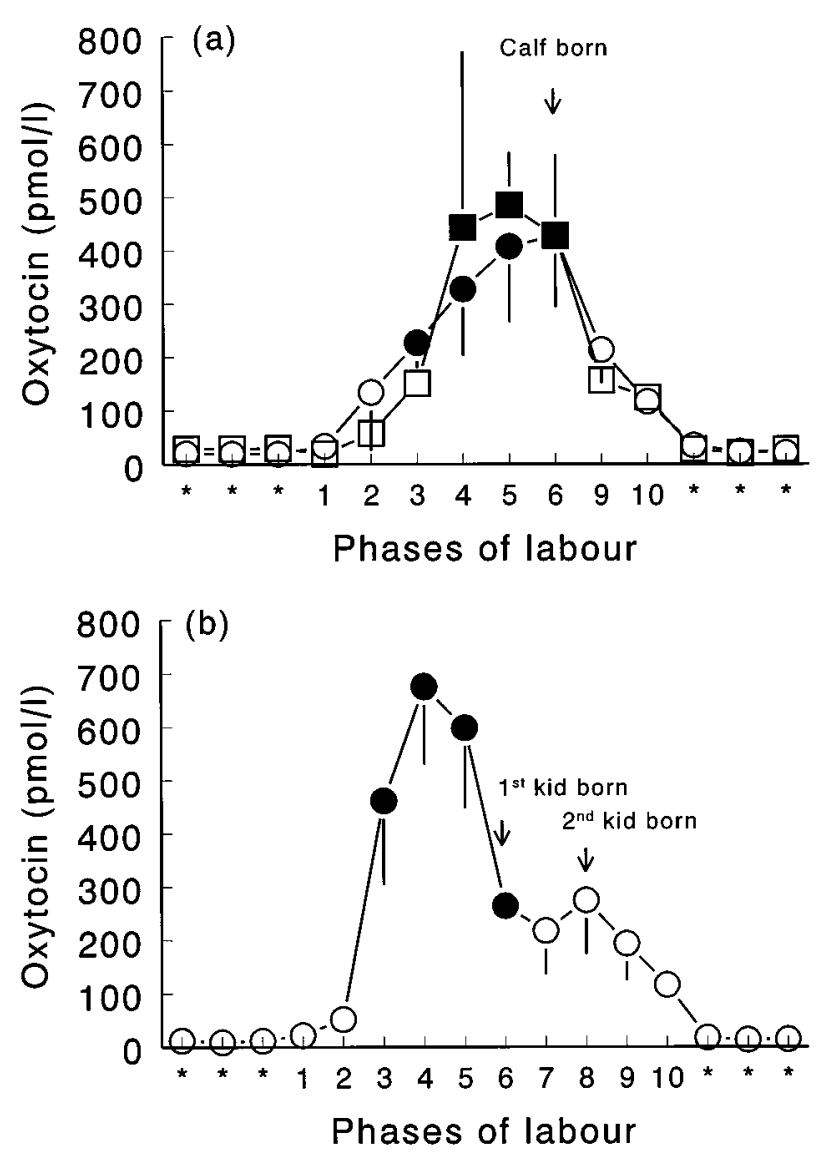

Figure 7 Plasma oxytocin concentration during parturition in five heifers that calved without help $(\bigcirc)$, five heifers that needed obstetrical assistance ( $\square$ ) (a), and six goats that kidded without help (b). Values are means \pm S.E.M. There were no significant differences between the two heifer groups. The S.E.M. values varied between 2.4 and 142.4 in heifers that calved without help, between 1.6 and 329.4 in heifers that needed obstetrical assistance, and between 0.7 and 158.8 in the goats. See Fig. 1 for further details.

those that did not, the high cortisol values during expulsion may have been partly due to the stress and pain that accompany all parturitions. On the day before parturition, the cortisol concentration in the goats tended to increase above the value that could be explained by diurnal variation (Olsson \& Dahlborn 1989), and, when labour started, cortisol levels increased stepwise. The values are comparable with those obtained during experimentally induced stress, involving the discomfort of having water administered by stomach tube. In that case, cortisol concentration increased to a mean value of $160 \mathrm{nmol} / 1$ (Eriksson et al. 1994), which is considerably lower than the mean value here of around $270 \mathrm{nmol} / \mathrm{l}$. Despite differences in absolute values between heifers and goats, the curve pattern in both species was characterized by the same continuous increase during the expulsion phase, ending with a peak when the calf/first kid was born. Therefore a combination of stress and pain could be the reason for the high plasma cortisol concentrations during expulsion.

We previously reported that changes in plasma catecholamine concentrations in goats were related to the different phases of labour and were highest during expulsion of the kids (Hydbring et al. 1997). These results are supported here, and similar results have been obtained in humans (Neumark et al. 1985, Costa et al. 1988, Maheux et al. 1996) and sheep (Eliot et al. 1981). However, Rausch et al. (1989) found that plasma adrenaline and noradrenaline did not change during parturition in cows, whereas Rainforth et al. (1990) and Diehl (1990) reported higher noradrenaline and adrenaline concentrations during difficult births in cows. Our results give some support to the observations of the latter authors. Thus heifers with difficult parturitions had higher mean levels of adrenaline and noradrenaline, but also showed greater individual variation than the other group. This indicates that higher peak values were reached in the assisted heifers. Furthermore, adrenaline and noradrenaline concentrations correlated throughout labour in assisted heifers, in contrast with the other group, showing that a massive discharge of the sympathetic nervous system was maintained for a long time in heifers with dystocia.

Increased $\beta$-endorphin concentrations around parturition have been reported previously in cows (Aurich et al. 1993), women (Chan et al. 1993, Fajardo et al. 1994, McLean et al. 1994) and rats (Wardlaw \& Frantz 1983). $\beta$-Endorphin increased throughout labour in the goats, whereas in heifers it only increased significantly after parturition in the group that needed assistance. However, $\beta$-endorphin levels already showed a tendency to be higher in assisted heifers at the first blood sampling, and they remained higher throughout labour, indicating that $\beta$-endorphin concentration is related to labour-related difficulties in heifers. This could be compared with labour in women: pain intensity correlated positively with the concentration of $\beta$-endorphin in the plasma (Bacigalupo et al. 1990).

Met-enkephalin has a short half-life in plasma (Boarder $\&$ McArdle 1986), and, like $\beta$-endorphin, acts primarily in the brain. Its rapid degradation may explain some of the variation between samples and animals. However, our results confirmed earlier findings in cows, sampled on a single occasion during parturition, in which plasma metenkephalin levels increased during labour (Aurich et al. 1990, Dobrinski et al. 1991). In the goats and assisted heifers, the met-enkephalin concentration correlated with that of noradrenaline and adrenaline. This correlation could have been due to their synchronized release from the adrenal medulla combined with rapid inactivation.

Concentrations of vasopressin and oxytocin increased in both cows and goats during expulsion. It is well known that oxytocin is released during labour, mainly due to the Ferguson reflex, and our results support earlier findings in 
nanny goats (Folley \& Knaggs 1965, McNeilly et al. 1972), cows, ewes, mares and women (Fitzpatrick \& Walmsley 1965, Forsling et al. 1979). However, the extent of vasopressin involvement during parturition is still largely unknown. Elevated vasopressin concentrations around parturition have been reported for sheep (Alexander et al. 1974) and pigs (Lawrence et al. 1995), but not for humans (Leake \& Weitzman 1979, DeVane 1985, Mauri et al. 1994). The last-mentioned result is somewhat surprising since labour involves intense muscular work, and exercise can induce the release of vasopressin in a dose-related fashion in humans (Wade 1984). High vasopressin levels during labour could also be explained by increased plasma osmolality (Landgraf et al. 1983) and haemorrhage (Larsson et al. 1978, Olsson et al. 1987). The increases in vasopressin during expulsion in both goats and heifers may therefore be secondary to several causes. However, in the goats the vasopressin rose to high levels comparable with those observed in heifers that needed assistance, whereas the rise was much smaller in the other heifer group. The difference between the heifer groups became apparent when intervention started, which indicates a direct correlation between stress and pain and high levels of vasopressin.

In addition to stress and pain, exercise is known to increase vasopressin in some species, as mentioned above, as well as corticosteroid levels in cattle (Kuhlmann et al. 1985), sheep (Bell et al. 1983) and other species (Snow \& Rose 1981, Valberg et al. 1989, Jensen-Waern \& Nyberg 1993). Furthermore, exercise increases adrenaline and noradrenaline in cattle (Blum et al. 1979) and horses (Snow et al. 1992), $\beta$-endorphin and met-enkephalin in humans (Sommers et al. 1990, Sforzo 1989) and oxytocin in rats (Kasting 1988). Therefore, in addition to stress and pain, muscle work during kidding and calving should be considered to contribute to the elevated hormonal concentrations during expulsion.

Although plasma concentrations of all the hormones investigated increased during parturition, the pattern of the increases differed. One explanation could be the different release times and half-lives of the hormones. For instance, half-lives range from $2 \mathrm{~min}$ or less for the catcholamines to as long as $3 \mathrm{~h}$ for cortisol (Kutsky 1973), the latter probably explaining the general lack of correlation between increases in cortisol and the other hormones. Nevertheless, it is noteworthy that the correlation between increases in these other hormones was striking in the heifers needing help in contrast with the other heifer group and the goats. This supports the hypothesis that all the hormonal systems investigated here are activated in relation to severity of labour albeit to a different degree.

It is concluded that the hormonal changes during labour are related to the phase of labour and the degree of difficulty encountered. Hormonal peaks were reached around the time of expulsion, indicating that they were associated with muscle work, stress and pain rather than metabolic effects. Vasopressin reached high levels in goats, and was the only hormone with a higher plasma concentration in heifers that needed assistance than in the other group, indicating that it is released in order to deal with labour-induced pain.

\section{Acknowledgements}

This work was supported by the Swedish Medical Research Council (project 3392), Swedish Farmer's Foundation for Agricultural Research, and Agria Insurance Ltd. We thank Agr Gudrun Tengroth, Mrs Lena Hagenvall, Mrs Åsa Eriksson and Mrs Inger Lind for providing excellent technical assistance and taking good care of the animals.

\section{References}

Alexander D, Bashore R, Britton H \& Forsling M 1974 Maternal and fetal arginine vasopressin in the chronically catheterised sheep. Biology of the Neonate 25 242-248.

Apostolakis E, Longo L \& Yellon S 1991 Regulation of basal adrenocorticotropin and cortisol secretion by arginine vasopressin in the fetal sheep during late gestation. Endocrinology 129 295-300.

Aurich J, Dobrinski I, Hoppen H \& Grunert E $1990 \beta$-Endorphin and met-enkephalin in plasma of cattle during pregnancy, parturition and the neonatal period. Journal of Reproduction and Fertility $\mathbf{8 9}$ 605-612.

Aurich J, Dobrinski I, Hoppen H \& Grunert E 1993 Stimulation of release of $\beta$-endorphin and oxytocin by prostaglandin $\mathrm{F}_{2 \alpha}$ in cattle at parturition. Journal of Reproduction and Fertility 97 161-166.

Bacigalupo G, Riese S, Rosendahl H \& Saling E 1990 Quantitative relationships between pain intensities during labor and $\beta$-endorphin and cortisol concentrations in plasma. Decline of the hormone concentrations in the early postpartum period. Journal of Perinatal Medicine 18 289-296.

Barragry T 1975 The pharmacological induction of parturition. Irish Veterinary Journal 29 71-75.

Bell A, Bassett J, Chandler K \& Boston R 1983 Fetal and maternal endocrine responses to exercise in the pregnant ewe. Journal of Developmental Physiology 5 129-141.

Berglund B, Philipsson J \& Danell Ö 1987 External signs of preparation for calving and course of parturition in Swedish dairy cattle breeds. Animal Reproduction Sciences 15 61-79.

Blum J, Bianca W, Naf F, Kunz P, Fischer J \& DaPrada M 1979 Plasma catecholamine and parathyroid hormone responses in cattle during treadmill exercise at simulated high altitude. Hormone and Metabolic Research 11 246-251.

Boarder M \& McArdle W 1986 Breakdown of small enkephalin derivatives and adrenal peptide E by human plasma. Biochemical Pharmacology 35 1043-1047.

Brooks A \& Challis J 1988 Regulation of the hypothalamic-pituitaryadrenal axis in birth. Canadian Journal of Physiology and Pharmacology 66 1106-1112.

Burns J 1970 Relation between blood levels of cortisol and duration of human labour. In Proceedings of the Physiological Society, July 12P.

Carter C \& Altemus M 1997 Integrative functions of lactational hormones in social behavior and stress management. Annals of the New York Academy of Sciences 807 164-174.

Challis J \& Mitchell B 1981 Hormonal control of preterm and term parturition. Seminars in Perinatology 5 192-202.

Challis J, Kendall J, Robinson J \& Thorburn G 1977 The regulation of corticosteroids during late pregnancy and their role in parturition. Biology of Reproduction 16 57-69. 
Chan E, Smith R, Lewin T, Brinsmead M, Zhang H, Cubis J, Thornton K \& Hurt D 1993 Plasma corticotropin-releasing hormone, $\beta$-endorphin and cortisol inter-relationships during human pregnancy. Acta Endocrinologica 128 339-344.

Chard T 1971 Recent trends in the physiology of the posterior pituitary. Current Topics in Experimental Endocrinology 1 81-120.

Comline R, Nathanielsz P, Paisey R \& Silver M 1970 Cortisol turnover in the sheep foetus immediately prior to parturition. In Proceedings of the Physiological Society, July 141P-142P.

Costa A, DeFilippis V, Voglino M, Giraudi G, Massobrio M, Benedetto C, Marozio L, Gallo M, Molina G, Fabris C, Bertino E \& Licata D 1988 Adrenocorticotropic hormone and catecholamines in maternal, umbilical and neonatal plasma in relation to vaginal delivery. Journal of Endocrinological Investigation 11 703-709.

Cox R 1975 The endocrinologic changes of gestation and parturition in the sheep. Advances in Veterinary Science and Comparative Medicine 19 287-305.

DeVane G 1985 Vasopressin levels during pregnancy and labor. Journal of Reproductive Medicine 30 324-327.

Diehl T 1990 Katecholamine und Metaboliten vor, während und nach der Geburt beim Rind. In Inaugural Dissertation. München: Tierarztlichen Fakultät Ludwig Maximilians Universität.

Dobrinski I, Aurich J, Grunert E \& Hoppen H 1991 Endogene Opioide Peptide beim Rind während Trächtigkeit, Geburt und Neugeborenphase. Deutsche Tierarztliche Wochenschrift 98 205-244.

Eliot R, Klein A, Glatz T, Nathanielsz P \& Fischer D 1981 Plasma norepinephrine, epinephrine, and dopamine concentrations in maternal and fetal sheep during spontaneous parturition and in premature sheep during cortisol-induced parturition. Endocrinology 108 1678-1682

Eriksson L, Hydbring E, Tuomisto L, MacDonald E, Kokkonen U-M \& Olsson K 1994 Intraruminal fluid administration to goats: effects of handling and fluid temperature. Acta Veterinaria Scandinavica 35 289-298.

Fajardo M, Florido J, Villaverde C, Oltras C, González-Ramirez A \& González-Gómez F 1994 Plasma levels of $\beta$-endorphin and ACTH during labor and immediate puerperium. European Journal of Obstetrics, Gynecology, and Reproductive Biology 55 105-108.

Fitzpatrick R \& Walmsley C 1965 The release of oxytocin during parturition. In Advances in Oxytocin Research, pp 51-73. Ed J Pinkerton. Oxford: Pergamon Press.

Flint A, Kingston E, Robinson J \& Thorburn G 1978 Initiation of parturition in the goat: evidence for control by foetal glucocorticoid through activation of placental $\mathrm{C}_{21}$-steroid $17 \alpha$-hydroxylase. Journal of Endocrinology 78 367-378.

Folley S \& Knaggs G 1965 Levels of oxytocin in the jugular vein blood of goats during parturition. Journal of Endocrinology 33 301-315.

Forsling M, MacDonald A \& Ellendorff F 1979 The neurohypophysial hormones. Animal Reproduction Science 2 43-56.

Fuchs A \& Saito S 1971 Pituitary oxytocin and vasopressin content of pregnant rats before, during, and after parturition. Endocrinology 88 574-578.

Heuwieser W, Hartig U, Offeney F \& Grunert E 1987 Zur Bedeutung von Glukokortikoiden als Streßarameter beim Rind im peripartalen Zeitraum. Journal of Veterinary Medicine Series A Animal Physiology, Pathology, and Clinical Veterinary Medicine 33 178-187.

Hudson S, Mullford M, Whittlestone W \& Payne E 1975 Bovine plasma corticoids during parturition. Journal of Dairy Science $\mathbf{5 9}$ 744-746.

Hydbring E \& Olsson K 1995 Stress and pain during parturition. In Proceedings of the Spring Conference of the Association of Veterinary Anaesthetists, Turku, Finland, p 63.

Hydbring E, MacDonald E \& Olsson K 1997 Radiotelemetrically recorded blood pressure and heart rate changes in relation to plasma catecholamine levels during parturition in the conscious, unrestrained goat. Acta Physiologica Scandinavica 161 295-302.
Jensen-Waern M \& Nyberg L 1993 Valuable indicators of physical stress in porcine plasma. Zentralblatt für Veterinärmedizin Reihe A $\mathbf{4 0}$ 321-327.

Kasting N 1988 Simultaneous and independent release of vasopressin and oxytocin in the rat. Canadian Journal of Physiology and Pharmacology 66 22-26.

Kendrick K, Keverne E, Hinton M \& Goode J 1991 Cerebrospinal fluid and plasma concentrations of oxytocin and vasopressin during parturition and vaginocervical stimulation in the sheep. Brain Research Bulletin 26 803-807.

Kitchell R 1987 Problems in defining pain and peripheral mechanisms of pain. Journal of the American Veterinary Medical Association 191 1195-1199.

Kitts D 1985 Peripartal endocrine changes and the initiation of lactation in ewes of diverse breeds. Growth 49 176-189.

Kuhlmann W, Hodgson D \& Fedde M 1985 Respiratory, cardiovascular, and metabolic adjustments to exercise in the Hereford calf. Journal of Applied Physiology 58 1273-1280.

Kutsky R 1973 Handbook of Vitamins and Hormones. New York: Van Nostrand Reinhold Company.

Landgraf R, Schulz J, Eulenberger K \& Wilhelm J 1983 Plasma levels of oxytocin and vasopressin before, during and after parturition in cows. Experimental and Clinical Endocrinology 81 321-328.

Larsson B, Olsson K \& Fyhrquist F 1978 Vasopressin release induced by hemorrhage in the goat. Acta Physiologica Scandinavica 104 309-317.

Lawrence A, Petherick J, McLean K, Deans L, Chirnside J, Vaughan A, Gilbert C, Forsling M \& Russel J 1995 The effects of chronic environmental stress on parturition and on oxytocin and vasopressin secretion in the pig. Animal Reproduction Science $\mathbf{3 8}$ 251-264.

Leake R \& Weitzman R 1979 Developmental pharmacokinetics of the posterior pituitary hormones. Clinics in Perinatology 6 $65-85$.

Liggins GC, Fairclough RJ, Grieves SA, Forster CS \& Knox BS 1977 Parturition in the sheep. Ciba Foundation Symposium 47 5-30.

McFeely R \& Ganjam V 1976 Induction of parturition in farm animals. Annales de Recherches Veterinaires 7 151-156.

McLean M, Thompson D, Zhang H, Brinsmead M \& Smith R 1994 Corticotrophin-releasing hormone and $\beta$-endorphin in labour. European Journal of Endocrinology 131 167-172.

McMillen I, Phillips I, Ross J, Robinson J \& Owens J 1995 Chronic stress: the key to parturition? Reproduction, Fertility and Development 7 499-507.

McNeilly A, Martin M, Chard T \& Hart I 1972 Simultaneous release of oxytocin and neurophysin during parturition in the goat. Journal of Endocrinology 52 213-214.

Maheux P, Bonin B, Dizazo A, Guimond P, Monier D, Bourque J \& Chiasson J-L 1996 Glucose homeostasis during spontaneous labor in normal human pregnancy. Journal of Clinical Endocrinology and Metabolism 81 209-215.

Mauri A, Ticconi C, Volpe A \& Piccione E 1994 Is vasopressin involved as a local mediator in the mechanism of parturition? Annals of the New York Academy of Sciences 734 372-379.

Neumark J, Hammerle A \& Biegelmayer C 1985 Effects of epidural analgesia on plasma catecholamines and cortisol in parturition. Acta Anaesthesiologica Scandinavica 29 555-559.

Nyman S, Hydbring E \& Dahlborn K 1996 Is vasopressin a 'stress hormone' in the horse? Pferdeheilkunde 12 419-422.

Olsson K \& Dahlborn K 1989 Fluid balance during heat stress in lactating goats. Quarterly Journal of Experimental Physiology $\mathbf{7 4}$ 645-659.

Olsson K, Andén N-E, Johansson K \& Thornström U 1987 Effects of acute haemorrhagic hypotension during pregnancy and lactation in conscious goats. Acta Physiologica Scandinavica 129 479-487. 
Rainforth L, Knott M \& Clemens E 1990 Calving and stress hormones of calves. Beef Cattle Report 56 13-15.

Rausch W, Hofer A, Gemeiner M \& Möstl E 1989 Katecholaminund Cortisolkonzentrationen im Plasma von Rindern um die Geburt. Journal of Veterinary Medicine Series A Animal Physiology, Pathology, and Clinical Veterinary Medicine 36 218-224.

SAS Institute Inc. 1996 SAS User's Guide. Cary, NC: Statistics.

Seren E, Bono G, De Fanti C \& Matteuzzi A 1977 Peripheral plasma levels of oestrone, oestradiol $17 \beta$, oestradiol $17 \alpha$, oestradiol, progesterone, luteinizing hormone and cortisol in pre and post-parturient Friesian cows. Archivio Veterinario Italiano 28 152-160.

Sforzo G 1989 Opioids and exercise. An update. Sports Medicine 7 109-124.

Snow D \& Rose R 1981 Hormonal changes associated with long distance exercise. Equine Veterinary Journal 13 195-197.

Snow D, Harris R, MacDonald I, Forster C \& Marlin D 1992 Effects of high-intensity exercise on plasma catecholamines in the thoroughbred horse. Equine Veterinary Journal 24 462-467.

Soma L 1985 Behavioral changes and the assessment of pain in animals. In Proceedings of the Second International Congress of Veterinary Anesthesia, pp 38-41. California: Sacramento.

Sommers D, Loots J, Simpson S, Meyer E, Dettweiler A \& Human J 1990 Circulating met-enkephalin in trained athletes during rest, exhaustive treadmill exercise and marathon running. European Journal of Clinical Pharmacology 38 391-392.

Stock S \& Uvnäs-Moberg K 1988 Increased plasma levels of oxytocin in response to afferent electrical stimulation of the sciatic and vagal nerves and in response to touch and pinch in anaesthetized rats. Acta Physiologica Scandinavica 132 29-34.
Strott C, Sundel H \& Stahlman M 1974 Maternal and fetal plasma progesterone, cortisol, testosterone and $17 \beta$-estradiol in preparturient sheep: response to fetal ACTH infusion. Endocrinology 95 1327-1339.

Taverne M, Bevers M, Van der Weyden G, Dieleman S \& Fontijne P 1988 Concentration of growth hormone, prolactin and cortisol in fetal and maternal blood and amniotic fluid during late pregnancy and parturition in cows with cannulated fetuses. Animal Reproduction Science 17 51-59.

Thorburn G, Hollingworth S \& Hooper S 1991 The trigger for parturition in sheep: fetal hypothalamus or placenta? Journal of Developmental Physiology 15 71-79.

Valberg S, Essen Gustavsson B, Lindholm A \& Persson S 1989 Blood chemistry and skeletal muscle metabolic responses during and after different speeds and durations of trotting. Equine Veterinary Journal 21 91-95.

Wade C 1984 Response, regulations, and actions of vasopressin during exercise: a review. Medicine and Science in Sports and Exercise $\mathbf{1 6}$ 506-511.

Wardlaw S \& Frantz A 1983 Brain $\beta$-endorphin during pregnancy, parturition, and the postpartum period. Endocrinology 113 1664-1668.

Wood C \& Keller-Wood M 1991 Induction of parturition by cortisol: effects on negative feedback sensitivity and plasma CRF. Journal of Developmental Physiology 16 287-292.

Received 2 April 1998

Revised manuscript received 20 August 1998 Accepted 1 September 1998 